\title{
The Thinking of Outdoor Training Course Teaching in College Physical Education
}

\author{
Qiang Ma
}

University of Electronic Science and Technology of China, Sichuan Chengdu, 610054, China

Keywords: Colleges, Physical teaching, Outdoor training course.

\begin{abstract}
. outdoor training is a kind of effective education mode of practice first and then know, its application to the college physical education, is not only beneficial to rich the teaching contents and teaching forms of physical education, prompt physical education to be interesting challenging, and effective, but also conform to the developing trend of modern curriculum reform, cultivate students'comprehensive quality and practical ability, realize the goal of physical education in colleges. This paper started with the overview of outdoor training characteristics, made analysis of the significance of outdoor training course teaching in college physical education, and put forward the specific strategies of outdoor training courses education, expecting to promote the college physical education teaching reform, and help to promote the all-round development of students.
\end{abstract}

\section{Overview of outdoor training}

Outdoor training is a kind of new modern education mode, which need according to the knowledge background and professional characteristics of the training object, targeted design project activities, to make the training object obtain inspiration in the process of the challenging project, and cultivate good psychological quality, flexible social strain capacity, strong will quality, and positive attitude towards life of training objects. Outdoor training is different from the simple combination of physical sports and entertainment, but is an effective education way has educational function, in the field of education, the outstanding features of outdoor training manifest in the following areas:

\section{Pay attention to experience and inspiration}

For students, outdoor training is essentially a way of experiential learning, which adequately reflected the education concept take the student as the main body, the students would improve self-awareness in the process of participation in outdoor training program, cultivate team consciousness, realize the feeling of superiority and success gain through their own efforts, and enhance students'self-confidence.

\section{The diversity of project activities}

Place for conducting training can be either indoor, can also be the outdoor place, and training programs won' t be affected by bad weather conditions, which enhance the flexibility and diversity of the project activity. In the process of training, emphasize the collective collaboration, which requires students in each group must try their best to complete the project challenge, fully manifests personal value in the team, and enhance the team's overall strength.

\section{Teach through lively activities}

Outdoor training must be well-aligned carried out under the guidance of teachers, strictly follow the teaching procedures, to ensure that every link of training is carried out in a planned way. At the same time, the outdoor training project is interesting, challenging, organized, can help students gain new 
knowledge and experience in the training project full of entertainment and experience, and achieve the effect of teaching through lively activities.

\section{Emphasis on growth of both individual and collective}

In outdoor training, the teacher only responsible for clearly telling students the project training content, training requirements and security announcements, and require the students in the group unitive and cooperative to complete the project training task. In the process, each student' s personal effort is closely related to completion of training program, so the students must redouble their efforts to enhance collective strength of the team, which is beneficial to improve the students'ability of self education.

\section{The significance of outdoor training course teaching in college physical education}

\section{Is beneficial to practice quality education idea}

Quality education attaches great importance to the long-term development of people, and takes the improvement of people' s all aspects of literacy as education target. Through quality education in colleges, can optimize and improve the students'individual character, and make their intelligence and ability to get better development, to lay the solid foundation for their future growth. Scientifically education is the basic idea of outdoor training, which is the in full compliance with the school education requirements. All the content involved in outdoor training is developed by professionals according to the actual situation of students, and each item has stood the test of the feasibility and practice. The training projects not only have a certain improvement effect on college students'physical quality, but also can improve their level of physical and mental health. Due to the traditional way of education is hard to cultivate high quality and compound creative talent, and the outdoor training applies the education way of practice first and then know, which has a positive impact for advancing the quality education and the cultivation of high-quality talents.

\section{Is beneficial to college students'all-round development}

The era of progress and the development of the society led to constant increase of all kinds of new things, because college students have a very strong thirst for knowledge, they are full of curiosity for all the new things, especially the entertaining and challenging sports projects are their favorite. However, by investigated the physical education in some domestic colleges, we found that most colleges still adopt the traditional method of physical education, teachers are the main body in the whole teaching, the content is boring and monotonous, can not meet the students'interest, also is hard to inspire their participation enthusiasm, and leading to the barely satisfactory teaching effect of college physical education. Some projects of outdoor training are not only very strong entertaining and interesting, also are certain challenging, when students complete the project, not only can feel happy, also can experience the joy of success, which play an important role in promoting the all-round development of morality, intelligence and physique for college students.

\section{Is beneficial to complement the shortcomings of traditional physical education in colleges}

For a long time, with the influence of examination-oriented education, the education way in our country based on the knowledge teaching, and took the ultimate goal as made students understood and mastered more knowledge and skills. Although the process of education system reform accelerated, and also began to emphasize the students as the main body of education, but in practice, education pattern takes teacher as dominating role and students as subsidiary role dose not change too much. Compared with the traditional education mode, outdoor training whether in teaching ideas, teaching methods, or in teaching practice, all reflects the obvious superiority. All projects of outdoor training take students as the center, and highlight the subject status of students in the teaching activities. The students'learning in outdoor training is designed activities to achieve a desired effect, and here teachers'teach is mainly create the external conditions and environment for students'practice 
and game, they play the role of inspiration and inductor. In the process of participation in training, students can experience the great happiness, and through challenge the higher level to improve them. It is thus clear that introduces outdoor training to the physical education in colleges can effectively supplement to the insufficient of the traditional physical education.

\section{The strategy of carrying out outdoor training course in college physical education}

\section{Reasonable construction of outdoor training course system}

To reasonable build training course system in colleges'physical teaching planning, on the basis of giving full consideration to the school facilities, staffed and other factors, to scientific arrange the course content. From an overall perspective, the colleges'outdoor training course can be divided into of two parts as theory course and practice course, specific content as follows:

1. The theory course system. Theory course is designed to teach students the origin, function, purpose, meaning, and other basic knowledge of outdoor training, and introduce the discipline knowledge closely associated with outdoor training, especially focus on safety education, make students understand the safety matters when participate in the project, and master the knowledge about sports injury care. In theory course teaching, teachers can use multimedia teaching means, improve teaching effectiveness. At the same time, the teacher can also be integrated into the simple training projects, such as self-introduction, tongue twisters, guess riddles, and other project activities.

2. Practice course system. Practical courses can be divided into the following two stages: the first stage is given priority to basic quality training, combine outdoor training content with physical education teaching contents, make full use of the sports equipment to carry out the project training, improve the athletic ability, the basic physical quality and physical coordination control ability of the students. The training projects in this stage mainly include the trust buttock, tower speech, kangaroo jump, and the blind matrix and so on; is appropriate to use training way combine group projects with individual projects. The second stage is given priority to comprehensive quality training, focus on training students'ability to flexible use ability, team cooperation ability, planning and organization ability, management and decision-making ability, creative thinking ability, etc. The training projects in this phase can include the horizontal bar in air, the giant ladder, climbing, seek to live on wall, island survival, etc., these training projects can gradually move the training results to students'daily learning life, and change the students'attitude and behavior of life and learning.

\section{Improve the scientific outdoor training course teaching mode}

For outdoor training courses teaching, ready of related work is the key to ensure orderly sequences of training. Before the official start of the project, therefore, teachers should know the details all the students who involved in the training, according to the different types of students, make targeted training course plan. When training project started, on the premise of ensure the safety of students, the teacher may conduct specifically training of students who is fear of a certain training, thus can enhance the students'psychological enduring capacity. To further enhance the teaching effect of outdoor training courses at the same time, should as far as possible to teach students in accordance of their aptitude, and vary with each individual. Outdoor training course pattern can be roughly divided into the following several parts, which are experience, feeling, share, summary and application, each part has its own independence and connected to each other. Experience is the first step in the whole training, it is one kind of personal experience of training simulation scenario in the project, help to stimulate students'potential; feeling is a very important part, in this part, the student can have a fresh understanding on themselves; share is the process of the students tell the feeling of the training project to others, each share is an accumulation of experience; summary is the conclusion of the discussed results by all students, by combining with the characteristics of the training project, guide students to strengthen the cognition of training result; application is to apply what understood in outdoor training to the life situation, to achieve the purpose of practice what they learnt. The above parts go from the 
easy to the difficult and complicated, and from beginning to end, in the whole process the students both achieve the purpose of learning knowledge, and realize the enjoyment of learning.

\section{Using diverse ways of learning evaluation}

After the training course in physical education in colleges, teaching evaluation is an essential part, to achieve the expected teaching goal, the evaluation methods of outdoor training evaluation can be various, namely with the aid of all feasible evaluation method to evaluate training teaching process, this way of evaluation is focused on student achievement, and pay attention to the development of students'potential, through evaluation of the students can help them to be more self-confident, so that the students can constantly perfect and improve themselves in the evaluation. First of all, should highlight the comprehensive and integrity of the evaluation. When making the content of the evaluation, except to combine the characteristics of outdoor training should also be fully aware of the quality education requirements for students, and around the social practice ability of students to set up the corresponding evaluation content, must not limit the evaluation content in theory and operating knowledge, but rather to involve learning attitude, psychology, intelligence, strain capacity, and other aspects, and with the student' s individual situation as foothold to develop evaluation criteria. Secondly, the multiple evaluation methods can be organically combined together, to achieve the goal of complementary advantages. Due to the outdoor training is a dynamic process of change from beginning to end, if only use a certain evaluation method to evaluate students'grades are difficult to achieve objectivity and fairness, so, the evaluation can apply multiple evaluation methods together, so that we can make the evaluation results more objective and true. Thirdly, carry out characteristic evaluation. Can use the evaluation mode give priority to motivation, to improve the efficiency of education, to seize the moment in specific evaluation, when the students made a certain progress, can give them verbal or mental reward.

\section{Strengthen the development and utilization of outdoor training curriculum resources}

For the colleges'physical education, outdoor training course is a new type of teaching mode, which requires sufficient teaching resources, to ensure the effective implementation of the training course. Therefore, the colleges must pay attention to the development and utilization of outdoor training curriculum resources, concrete from the following three aspects: firstly is the emphasis on the development and utilization of human resources. The colleges should equip with physical education teachers of high comprehensive quality, which require physical course teachers should not only have rich teaching experience and solid theoretical knowledge, but also to understand the specialized knowledge as psychology and management, to make them be qualified in outdoor training teaching organization work. Secondly is attaches great importance to the development and utilization of resources. The colleges should choose suitable outdoor training teaching materials for higher physical education, also can form a research group to develop school-based teaching materials of outdoor training. At the same time, the colleges should equip the basic outdoor training material insurance, such as site, sports equipment, indoor insurance, etc. Thirdly, attaches great importance to the development and utilization of financial resources, the colleges should take the outdoor training costs into the budget, to insure smoothly implement of the training. The colleges in the same region, also can through colleges joint, joint venture construct training base, and provide more training projects for students. In order to alleviate the pressure of the insufficient funds, the colleges can also cooperate with the social outdoor training institutions, and make full use of project resources of social institutions, to ensure effective implementation of the outdoor training education mode.

\section{Conclusion}

In a word, introduce the outdoor training courses in colleges'physical education, is a kind of successful attempt in college physical education teaching mode innovation, and manifest the great application value in rich education and teaching activities, stimulate the students'participation enthusiasm, cultivate students'comprehensive quality and ability and so on. Therefore, the colleges 
should combine the school characteristics and the target of talent training, to reasonable set outdoor training course content in physical education, and increase the developing intensity of outdoor training curriculum resource, give full play to the positive role of outdoor training course in promoting the reform of physical education in colleges.

\section{Reference}

[1] Liu Bingze. The practical thinking of introduce outdoor training course teaching in college physical education, Contemporary sports science and technology, 2015 (7): 97-98.

[2] Zong Youzhi, Chang Youli, Qin Yiyu. The exploration of outdoor training course education in colleges'physical education, Valuable engineering, 2011 (3): 82-83.

[3] Zhu Jinyuan. The survey of introduce outdoor training course teaching in college physical education, Fight BBS (sports), 2010 (8): 102-103.

[4] Bai Zhixian. The feasibility study on carrying out the outdoor training course in Shijiazhuang colleges, Hebei Normal University, 2014.

[5] An Daqing. The study on carrying out the outdoor training course in colleges, Contemporary sports science and technology, 2014 (8): 141-142. 